\title{
ON THE TRIANGLE EQUALITY
}

\section{GRZEGORZ ŁYSIK}

Abstract. Given a norm on a vector space a natural question is when for given vectors the triangle equality holds, i.e., when the norm of a sum of vectors is equal to the sum of norms of vectors. It is well known that if the space is strictly convex, then the triangle equality holds if and only if the vectors belong to the same half-line emanating from the origin. In the note we give necessary and sufficient geometric conditions for the triangle equality in an arbitrary normed vector space. The conditions can be checked once the unit sphere is known.

Mathematics subject classification (2010): 46B20.

Keywords and phrases: Triangle equality, asymmetric normed spaces.

\section{REFERENCES}

[1] Y. A. Abramovich, C. D. Aliprantis And O. Burkinshaw, The Daugevet equation in uniformly convex Banach spaces, J. Funct. Anal. 97 (1991), 215-230.

[2] M. BARraA AND M. Boumazgour, Inner derivations and norm equality, Proc. Amer. Math. Soc. 130, 2 (2002), 471-476.

[3] S. CoBZAŞ, Functional Analysis in Asymmetric Normed Spaces, Birkhäuser, Basel, 2013.

[4] V. I. IstrăţESCU, Strict Convexity and Complex Strict Convexity, Theory and Applications, Marcel Dekker, Inc., New York and Basel, 1984.

[5] L. MaligrandA, Some remarks on the triangle inequality for norms, Banach J. Math. Anal. 2, 2 (2008), 31-41.

[6] R. NaKamoto And S. TAKahashi, Norm equality condition in triangular inequality, Sci. Math. Jpn. 55, 3 (2002), 463-466.

[7] R. RAJIĆ, Characterization of the norm triangle equality in pre-Hilbert $C^{*}$-modules and applications, J. Math. Inequalities 3, 3 (2009), 347-355.

[8] S. Romaguera And M. SANChIS, Semi-Lipschitz functions and best approximation in quasi-metric spaces, J. Approx. Theory 103, 2 (2000), 292-301.

[9] W. Rudin, Real and Complex Analysis, McGraw-Hill, New York, 1974.

[10] M. Schellekens, The Smyth completion: A common foundation for denotational semantics and complexity analysis, Electronic Notes in Theoret. Comput. Sci. 1 (1995), 535-556. 